\title{
La crítica literaria frente a las narrativas afrohispanoamericanas: generalizaciones y racialización
}

\author{
Literary Critic Before Afro-Hispanic American \\ Narratives: Generalizations and Racialization \\ A crítica literária face às narrativas afro-hispano- \\ americanas: generalizações e radicalização
}

\section{Silvia Valero}

UNIVERSIDAD DE CARTAGENA, COLOMBIA

Profesora de Literatura Latinoamericana en la Universidad de Cartagena, Colombia. Doctora en Literatura por la Université de Montréal. Sus principales ejes de investigación se concentran en las producciones de etnicidad en las narrativas afrohispanoamericanas. Últimas publicaciones: Mirar atrás: La importancia del pasado en los relatos de nación y negritud en la literatura afrocubana de entre siglos (Córdoba: Alción Editora, 2014), Identidades políticas en tiempos de afrodescendencia: autoidentificación, ancestralidad, visibilidad y derechos", en co-edición con Alejandro Campos García (Buenos Aires: Corregidor, 2015), "Afroepistemología y sensibilización en las narrativas históricas afrodescendientes del siglo XXI" en Identidades políticas..., y "Literatura y 'afrodescendencia': identidades políticas en la literatura afrolatinoamericana del siglo XXI", dossier coordinado para Revista de Crítica Literaria Latinoamericana 81 (2015). Correo electrónico: svalero@unicartagena.edu.co 


\section{Resumen}

El presente trabajo intenta problematizar la fuerza con que la retórica de las producciones de identidad "afrodescendiente" ha ingresado en la crítica literaria hispanoamericana de los últimos años, provocando, en algunos casos, lecturas generalizadoras y racializadas que naturalizan la idea de pre-existencia y transhistoricidad de un "ser afro".

Palabras claves: literatura afrohispanoamericana; crítica literaria; etnicidad afrodescendiente; ontologización

\section{Abstract}

This works tries to define as a problem the strength with rhetorics of the "afrodescendant" identity productions have entered in the Hispanic American literary criticism of recent years. It has provoked, in some cases, generalizing and racializing readings that naturalize the idea of preexistence and transhistoricity of "being afro".

Keywords: Afro-Hispanic American literature; literary criticism; ethnicity; afrodescendant; ontologize

\section{Resumo}

O presente trabalho visa problematizar a força com que a retórica das produções de identidade "afrodescendente" ingressou na crítica literária hispano-americana dos últimos anos, resultando em alguns casos, leituras generalizadoras e racializadas que naturalizam a ideia de pré-existência e transhistoricidade de um "ser afro".

Palavras-chave: literatura afro-hispano-americana; crítica literária; etnicidade afrodescendente; ontologização

RECIBIDO: 01 DE ABRIL DE 2015. ACEPTADO: 23 DE JULIO DE 2015. DISPONIBLE EN LÍNEA: 01 DE ENERO DE 2016

Cómo citar este artículo:

Valero, Silvia. "La crítica literaria frente a las narrativas afrohispanoamericanas: generalizaciones y racialización". Cuadernos de Literatura 20.39 (2016):

52-41.http://dx.doi.org/10.11144/Javeriana.cl20-39.clna 


\section{Introducción}

Difícilmente, como adelantábamos en otro trabajo, quien pronunció la frase "Entramos negros y salimos afrodescendientes", luego de la Conferencia Preparatoria de las Américas en Santiago de Chile en el año 200o, habrá previsto el avasallante movimiento socio-político-cultural, y fundamentalmente epistemológico, que se avecinaba (Campos García, Introducción 15). El cambio de (auto)denominador no se limitó solo a ello, es decir, a reemplazar el significante colonial "negro" y diferenciarse, al mismo tiempo, del término "African American", usado para designar a los descendientes de africanos nacidos en Estados Unidos, sino que, y en función de lo que interesa a este artículo, desarrollaría una serie de condicionantes, características y categorías que permearían el campo literario, sobre todo en lo que se refiere a la producción de subjetividades. Al mismo tiempo, impulsaría un despegue de trabajos críticos e investigativos no existentes hasta pocos años antes en el ámbito literario hispanoamericano. Esta apertura, sin embargo, no se produciría inmediatamente, debido, en particular, al poco espacio dedicado por la academia a la literatura afrohispanoamericana.

En una investigación que llevé a cabo en el año 2005, titulada Hacia una genealogía "afrodescendiente" para la literatura colombiana: problemas de identidad y corpus, concluía en que fue en las décadas de los sesenta, setenta y ochenta, a través de académicos norteamericanos en vínculo directo con su propia realidad en materia de blackness, que algunos escritores comenzaron a ser reunidos en una categoría que incluía lo "afro" (afrocolombianos, afrovenezolanos, afrocostarricenses, etc.) obteniendo, así, una plataforma crítica que los "descubrió", sobre todo en Estados Unidos, en tanto los primeros libros solo fueron publicados allí y en inglés. Paradójicamente, poco y nada podía hallarse dentro del campo académico de este lado del continente aún en los inicios del siglo XXI en cuanto a estudios sistemáticos de la literatura, afrocolombiana en el caso que estudiaba, pero que bien podía ser extendido más allá de esos límites nacionales (Valero, “¿De qué hablamos..."). Mucho de ello ha cambiado, y vertiginosamente en los últimos años, en los que, además de incrementarse las publicaciones críticas, la creación literaria misma ha tomado un cauce que la ubica como uno de los discursos más significativos dentro de los correspondientes al sostenimiento de la retórica cultural afrodescendiente ${ }^{1}$.

1 Extiendo estas reflexiones en la presentación del dossier dedicado a las literaturas afrolatinoamericanas del siglo XXI de Revista de Crítica Literaria Latinoamericana Nro. 81 (2015), "Literatura y 'afrodescendencia': identidades políticas en la literatura afrolatinoamericana del siglo XXI". Para el vínculo entre políticas de identidad y discursos desde y sobre la afrodescendencia, ver Identidades políticas en tiempos de la afrodescendencia: auto-identificación, ancestralidad, visibilidad y derechos. 
Ahora bien, el terreno que ha ido ganando el campo crítico se me aparece, en algunas ocasiones, desbordado por dicha retórica, cuando se la asume de un modo tal que es pasada por alto su contingencia, en tanto producto de un momento histórico preciso asociado a las políticas de identidad y al giro multicultural. De este modo, se formulan propuestas/respuestas cuyo resultado es la naturalización de un "ser afro", que, por un lado, reproduce aquello mismo que se busca destruir, es decir, folklorizaciones y estereotipias, y, por otro, con la repetición casi automática de determinados conceptos, produce una banalización de los mismos.

La reproducción del campo semántico que sostiene el discurso que hegemoniza las producciones de identidades políticas produce aquello sobre lo cual se alertaba desde otro campo de investigación, esto es, la no diferenciación entre alteridades históricas e identidades políticas transnacionales:

[...] estas últimas son un producto de la globalización por dos caminos posibles: 1) pueblos que estuvieron siempre constituidos y bastante aislados [...] y que ahora se ven empujados a "visibilizarse", "etnificarse" y racializarse en términos que les son novedosos; y 2) segmentos de la sociedad con la marca racial de la negritud y, en algunos casos, portadores de tradiciones diferenciadas, cuya identidad pasa ahora a obedecer la pautas de un guión fijo introducido por el proceso de globalización y endosado por los estados nacionales bajo la presión de los agentes globalizadores, inspirados en concepciones de raza de los Estados Unidos [...]. (Segato 63)

En otras palabras, la investigadora argumenta que se crea un lenguaje desde el cual se conforma una hegemonía de sentido, es decir, se convierte en una articulación que define los términos desde los que debe pensarse la afrodescendencia.

Así, en la medida en que la literatura es también una fuente de recepción y producción de plataformas identitarias, tiene sentido pensar de qué manera la práctica literaria, tanto desde la creación como desde la crítica, se constituye en torno a la "cuestión etno-racial" en estas décadas. Ello, en cuanto condicionante tanto de los modos y términos de la representación, como en la recepción de esta por parte de los agentes que conforman el campo literario: lectores, críticos, academia.

En consonancia con lo anterior, si consideramos el giro que han dado algunos conceptos claves como "raza", "conciencia racial", "ser negro", y particularmente, "ser afrodescendiente", entre otros, me interesa detenerme en cierta mirada que explora la producción cultural afrodescendiente - en este caso, la literatura- en las últimas dos décadas. Pero esto implica, particularmente, reconocer que esta renovación conceptual responde a posicionamientos y epistemologías propias de la 
época y que, por ende, imposibilitan su utilización retrospectivamente para establecer una tradición literaria afrohispanoamericana que responda a premisas actuales.

Mi punto de partida, por consiguiente, es la consideración de que las redefiniciones de aquellos conceptos favorecieron la creación de un escenario en torno al cual se define lo que es ser o no ser "afro", y que el campo de las representaciones literarias contribuye a reforzar, en cuanto se produce una retroalimentación teórico-descriptiva que enmarca los lineamientos a partir de los cuales se va narrando el contenido de dicha identidad.

Con la perspectiva de lo expuesto hasta aquí, el propósito de este artículo se concentrará en responder las siguientes preguntas: ¿qué dificultades se impone a sí misma la crítica con sus propuestas/respuestas racializadas? ¿De qué manera aquellas redefiniciones en torno a categorías vinculadas a identidades "afro" dan lugar a un espacio en tensión dentro del mismo campo?

\section{La dificultad de la generalización}

Es en el contexto de racialización de sujetos y culturas desarrollado en las últimas décadas que el vuelco fundamental alrededor del concepto de "raza" manifiesto en las expresiones identitarias implica que, además de asumírsela como existente, ya no se erige exclusivamente con una connotación negativa, como denuncia de prácticas discriminatorias desde hegemonías "blancas", sino que se posiciona como un signo (Segato), esto es, con capacidad de significar positivamente en virtud de una contextualización histórica ligada a un origen - África - y un pasado común - la trata y la esclavitud-, siempre como identidad contrastante con respecto a las formaciones nacionales.

Con racialización me refiero al tratamiento que se da a las diferencias (fenotípicas, ancestrales, étnicas) entre grupos de individuos, como si respondieran a una naturaleza racial que los condiciona y estabiliza (Campos García, "Racialización"). Ahora bien, la racialización existe conectada a las teorías raciales dominantes, por lo cual su carácter es eminentemente político, cualquiera sea el espacio social del que emane. De allí, entonces, que mi interés se focalice en explorar algunas de las tendencias de la crítica que alimentan el sentido de racialización tal como se produce "desde abajo", esto es, desde los mismos grupos autoracializados. Si por un lado los abordajes de algunas obras y autores se apoyan en conceptos negativizados, tales como "blanqueamiento", "estereotipo", "primitivismo" para analizar las producciones desde el desmenuzamiento - y condena- de imaginarios coloniales, nacionales y postcoloniales a partir de la idea de que estos dictaminaron cruces relacionales basados en parámetros etnoraciales, en general excluyentes de la diferencia, por otro lado, cierto sector de la 
crítica recurre a los conceptos propios de los proyectos políticos autoafirmativos tales como "memoria ancestral", "conciencia racial", "autenticidad", identidad "afro", "afrodiasporicidad". El problema comienza, creo yo, cuando estas categorías de análisis, obviando su carácter situacional, se cargan de una naturaleza ontológica que, acusando un determinismo étnico-racial, redefinen a un sujeto afro-referenciado que responde necesariamente, en el sentido que le da al término Stuart Hall, a pautas pre-existentes. Aquellos parámetros de autodeterminación que afirman y refuerzan una diferencia esencial y que subyace no solo en textos literarios de autores que hablan desde la creación de su propia subjetividad tanto como en los de aquellos que lo hacen desde afuera ${ }^{2}$, han permeado el discurso crítico que los acompaña y nutre al asumir como inevitable dicha perspectiva. La particularidad de estos enfoques es que se han multiplicado al punto de ser asumidos como asertos de sentido común que orientan las prácticas de la crítica literaria.

Como ejemplo gráfico refería, en otra oportunidad (Valero, " ¿De qué hablamos..."), la anécdota de una escritora que cargaba con cierto remordimiento por sus declaraciones durante una entrevista, en la que sus propias respuestas habían probado, legítimamente, que su entrada en el mundo de las letras afrohispanoamericanas en cuanto a incursionar en el mundo religioso, por ejemplo, no había obedecido a un "determinismo etno-racial" sino que era resultado de situaciones netamente contingentes. Entiendo que frente a la ausencia de vulnerabilidades, victimizaciones y prejuicios raciales propios y ajenos que se desprendía de su propia voz, su posterior preocupación frente a lo relatado con respecto a sí misma actuaba como reflejo del actual imperativo étnico que aprueba ciertas identificaciones y desaprueba otras, marcando, de este modo, los límites históricos de "lo pensable" y "lo decible", sin tener en cuenta que aquellas identificaciones son procesos anclados en una praxis social que no está pre-determinada.

Esta hegemonía - como se dijo más arriba, en el sentido en que se convierte en una articulación que define los términos desde los que se piensa y se disputa la afrodescendencia-, presupone una narrativa paradigmática cuyo repertorio tópico obligado, a pesar de las diferencias en géneros, lenguajes y otros parámetros de representación, comparte intereses y visiones ligados a una "identidad afro" cuya esencia no debería ofrecer dudas.

Con la reificación de esas identidades racializadas en autores y personajes, se las está viendo no, como productos humanos e históricos, productores, a su vez

2 Entiendo que esto es lo que sucede, por ejemplo, con algunas novelas actuales de la literatura argentina que reviso en mi artículo "Afroepistemología y sensibilización en las narrativas históricas afrodescendientes del siglo XXI". 
y por eso mismo, de una realidad, sino como existentes naturalmente. Es decir, no se apoya en el proceso que, a mi juicio, se explica claramente con el concepto de identificación tal como lo describe Stuart Hall (Hall 21), sino que la identidad adopta un régimen fuerte de representación, si pensamos en la definición que de ella hacen Brubaker y Cooper.

En este sentido, el campo crítico se convierte en germen de dos situaciones problemáticas para sí mismo: por un lado, fomenta generalizaciones acríticas que solo reproducen un esquema pre-establecido, y por otro, permite prácticas de exclusión e inclusión dentro del mismo campo. Más concretamente: al perdurar en el empeño por encontrar "lo afro" hasta en textos que ahondan en problemáticas varias y no específicamente en construir una identidad etno-racial; al objetivar definiciones sobre lo que es o no "ser negro" o "afrodescendiente"; al no contextualizar las condiciones de posibilidad de autores y obras, esto es, marcos históricos, concepciones de la ciencia, escenarios político-culturales, es muy probable que el resultado sea la superficialidad y el lugar común. Directamente ligada a esta situación, encuentro que, en algunos casos, el auge de dicha re-etnización lleva consigo el conflicto de la fascinación de "lo negro", en cuyo fondo se abisma un paternalismo que, como tal, resulta soporte de una "negrofilia" que se une a los parámetros de idealización y exotización, que, paradójicamente, se pretenden negar. De alguna manera, lo que se hace no es otra cosa que prescribir y vincular dos posicionamientos esencialistas: el de considerar ciertas prácticas derivadas reflejamente de una identidad imputada y una poderosa determinación (Brubaker y Cooper) y el de establecer una correspondencia necesaria — otra vez Hall- entre pertenencia y comportamiento (Briones, "Teorías" 60).

En este punto resulta de importancia detenerse en algunas situaciones comunes vinculadas a las dos dificultades que se articulan con los procesos de generalización mencionados más arriba: 1. A la hora de clasificar autores, es habitual hallar la categorización indiscriminada de "afro" a cualquier escritor que fenotípicamente responda a determinadas características, con lo cual automáticamente se le adjudica una etnicidad y, por lo tanto, se esperan $-\mathrm{y}$ se encuentran-determinados lineamientos en su escritura. 2. Según aquel esquema de representación de lo que es ser o no ser afrodescendiente, se lleva a cabo el mecanismo mediante el cual se excluyen-incluyen escritores. En ambos casos, aunque diferentes, estamos hablando de generalizaciones que dudo conduzcan a un avance del campo de la crítica.

Vinculado a la primera dificultad, es decir, la proliferación de denominaciones "afros", quizás uno de los ejemplos más claros lo constituya la publicación en el 2010 de la Biblioteca de Literatura Afrocolombiana. Si por un lado es de 
destacar el valioso esfuerzo por recuperar y publicar la obra de autores desconocidos, olvidados o negados por la crítica, por otro, la inclusión de algunos autores resulta discutible. No se me escapa ni por un momento que esto sucede con cada antología que se publica: la discusión sobre quién debería haberse seleccionado y quién no, o por qué se incluyeron unos autores y no otros. Aceptando esto, sin embargo, me parece muy elocuente resaltar uno de los nombres que se me presenta problemáticos en cuanto a su inclusión en la Biblioteca con la etiqueta de autor afrocolombiano

Si entendemos los denominadores "afrodescendiente/afrocolombiano" ligados al origen africano, a la noción de libertad como propia de los pueblos esclavizados en las Américas, a la idea de "experiencia negra" para aludir, no solo a una comunidad imaginada, sino para unificar a ese colectivo en la también pretendida unicidad de una experiencia, entonces es por lo menos debatible la incorporación de la figura del poeta Candelario Obeso (1849-1884) en este grupo.

Como he señalado en trabajos anteriores (Valero, "Invisibilidades directas" y "Antologías"), la mayor parte de la obra de este autor, conformada por poemas de corte romántico, obras de teatro y algunas traducciones de material militar, ha sido obviada por la generalidad de la crítica para rescatar solamente Cantos populares de mi tierra (1877), poemario en el que Obeso representa las vicisitudes, costumbres y visiones de mundo de los bogas y montaraces "negros", "mulatos" y "zambos" de Mompox, es decir, subjetividades culturalmente alejadas del centro bogotano dominado por una élite blanco-mestiza e hispanófila. Como contracara de la inclusión de Obeso dentro de los parámetros de lo que significa hoy "ser afro", es importante la perspectiva desde la cual el autor se narraba a sí mismo:

[...] efectivamente, cómo supo S. E. que yo soi oriundo de África? Se me pone que S.E. emplea los ratos que le deja ocupados el arte de la dramática, en estudiar alguna cosa de más provecho i honra, la antropología, por ejemplo, porque así solamente pudo dar S. E. en el raro descubrimiento de que mis antepasados fueron animales de aquella rejión zoológica. (Obeso 276; las bastardillas son mías)

El mismo Obeso pone en evidencia que las especificidades históricas, tanto del contexto en el cual se había educado (el colegio Pinillos de Mompox), como en el que se movía y al cual quería pertenecer (la ciudad letrada bogotana), no aceptaba la activación de un tipo de etnicidad entre sus miembros como la que intenta adjudicársele hoy al poeta. Esto no implica negar la lucha que debió padecer Obeso frente a agravios fundados en prejuicios raciales y regionales y que son elocuentes en sus páginas. Sin embargo, nada de ello puede parangonarse con la 
búsqueda o expresión de una identidad "afro" tal como se la concibe actualmente y como queda demostrado en el párrafo antes citado. Son, precisamente, esas especificidades históricas las que condicionan las posibilidades de ser de las etnicidades, sus desenvolvimientos, sus formas, sus relaciones con otros procesos. En este mismo sentido, Manuel Zapata Olivella (1920-2004) reflexionaba en el número 35 de Letras Nacionales:

Candelario Obeso aparece proyectado, tal vez sin saberlo, por el proceso socioeconómico que nutre la literatura romántica y nativista en América. $\mathrm{Su}$ conciencia étnica nada en la incertidumbre. Los poemas de afirmación a la raza reflejan el paternalismo que desatan las lágrimas en el negro al verse finalmente sin cadenas. (Zapata Olivella 7)

Esta manifestación de Zapata Olivella sirve como fundamento para poner en duda el criterio de incorporación de la obra de Obeso a un conjunto de textos con un carácter "afrocentrado". A veces, las dificultades en la construcción de una diferencia cultural descontextualizada termina deviniendo performativa en el sentido de responder a las expectativas y demandas de un campo cultural o social, que se constituye hegemónico en cuanto a establecer pautas y parámetros de significación.

Una situación similar ocurre en el interesante artículo "El mestizaje radical de Manuel Zapata Olivella: raza, etnia y ciudadanía", en el que se establece con retroactividad en escritores de toda América, desde el siglo XIX hasta la actualidad, la existencia de un "pensamiento afro". El autor lee a escritores tan distantes, no solo en tiempo y espacio sino en locus de enunciación, como Candelario Obeso (Mompox, 1849 - Bogotá, 1884), Manuel Zapata Olivella (Lorica, 1920 - Bogotá, 2004), Arnoldo Palacios (Cértegui, Chocó - 1924), Jorge Artel (Cartagena, 1909 1994), W. E. B. Du Bois (Massachussets, 1868 - Ghana, 1963), Langston Hughes (Missouri, 1902 - Nueva York, 1967), Adalberto Ortiz (Esmeraldas, Ecuador 1914-2003), Arna Bontemps (Louisiana, 1902 - Nashville, 1973), Richard Wrigth (Mississippi, 1908 - París 1960), estableciendo así una especie de línea canónica en términos de un nacionalismo negro actualizado por las presentes corrientes de pensamiento denominadas afrodiaspóricas:

Para estos autores, cuanto más alejadas estén las comunidades afroamericanas de las autoridades del Estado, más libertad, autonomía y felicidad tendrán, y viceversa, lo cual configura una de las claves de la suficiencia/resistencia de larga duración en el contexto específico de cada país, que permiten comprender maniobras socio-políticas afrodiaspóricas. (Arboleda 444) 
Desde mi perspectiva, esta deshistorización de la etnicidad, en el sentido de constituir grupos que perfilan una continuidad identitaria a través del tiempo y el espacio, no tienen en cuenta las condiciones de existencia de estos escritores y, en algunos casos, sus cambios de posicionamientos, lo cual debería llevarnos a desconfiar de la universalización de cierto clivaje de carácter étnico, en el sentido de asignarle un peso invariable a esa diferenciación (Briones, La alteridad 110).

En los dos casos antes expuestos, se está en presencia de una selección acrítica en la que aspectos controvertidos y de variada índole, como el color de la piel, el fenotipo, la imaginación de una comunidad de origen e histórica, operan generalizando reductivamente, aunque suene paradójico, en cuanto se ignoran diferencias, matices, contextos, procesos históricos, y se evitan, así, las distinciones que, seguramente, pondrían en cuestionamiento tales filiaciones. Pero, sobre todo, se corre el riesgo de perder de vista la riqueza que distingue a cada narrador, poeta o dramaturgo (al reproducir siempre las mismas instancias).

En el caso de la segunda dificultad por generalización, esto es, los procesos de exclusión-inclusión dentro del mismo campo literario afrohispanoamericano, el "ser o no ser afro/negro"s se pone de manifiesto de manera explícita en expresiones críticas como las siguientes:

$[\ldots]$ hoy no es raro encontrar a intelectuales y escritores negros asalariados que no quieren saber nada de lo negro que ellos mismos son [...]. Dichos escritores afrodescendientes quieren ser aceptados por la cultura institucional y escriben como los blancos para los blancos, con la ilusión de ser aceptados entre los blancos, a pesar de todo. (Ruiz 174)

Entiendo aquí que el proceso de articulación entre la sujeción y la subjetivación, tal como la concibe Stuart Hall, queda fuera de juego en tanto la binariedad yo/otro o nosotros/ellos deviene necesaria y reproduce y valoriza la existencia de un sujeto unificado bajo el significante "negro" o "afrodescendiente", es decir, se concibe una hiperbólica unidad dentro de categorías sociales como "etnicidad" o "raza", al mismo tiempo que inexpugnables diferencias entre personajes pertenecientes a uno y otro grupo.

Así, la crítica literaria termina estableciendo espacios de tensión en el seno mismo de estas prácticas cuando adopta políticas de generalización basadas en la

3 No se puede pasar por alto las diferentes tradiciones epistemológicas que informan estos dos términos. La indistinción de la que hago uso en esta frase obedece a que el mismo autor del párrafo transcripto los utiliza de manera intercambiable. En cualquier caso, entiendo que ambos conceptos cargan, para dicho autor, con el mismo significado en cuanto a lo ya enunciado en este trabajo: comunidades de origen, históricas y actuales. 
racialización y con dinámicas de exclusión-inclusión, ambas conducentes a naturalizar un "ser afro". De allí también que el pretender que existe una común vivencia de imágenes desde la esclavitud hasta el presente que vincula la experiencia cultural de los escritores, determine una visión estática y descontextualizada de los mismos.

\section{Obras citadas}

Arboleda Quiñones, Santiago. "El mestizaje radical de Manuel Zapata Olivella: raza, etnia y ciudadanía”. Eds. A. Laó Montes, Claudia Mosquera-Lavé y C. Rodríguez Garavito. Debates sobre ciudadanía y políticas raciales en las Américas negras. Cali: Universidad del Valle, 2010. Impreso.

Briones, Claudia. La alteridad del "Cuarto mundo": una deconstrucción antropológica de la diferencia. Buenos Aires: Ediciones del Sol, 1998. Impreso. "Teorías performativas de la identidad y performatividad de las teorías". Tabula Rasa 6 (2007): 55-83. Impreso.

Brubaker, Rogers, y Frederick Cooper. "Au-delà de l' 'identité"'. Actes de la recherche en sciences sociales 139 (2001): 66-85. Impreso.

Campos García, Alejandro. Introducción. Identidades políticas en tiempos de afrodescendencia: auto-identificación, ancestralidad, visibilidad y derechos. Eds. Alejandro Campos García y Silvia Valero. Buenos Aires: Corregidor, 2015. 15-64. Impreso.

"Racialización, racialismo y racismo: un discernimiento necesario". Universidad de La Habana 273 (2012): 184-198. Impreso.

Hall, Stuart. “¿Quién necesita la identidad?”. Cuestiones de identidad. Eds. Paul de Gays y Stuart Hall. Buenos Aires: Amorrortu, 2003. 13-38. Impreso.

Identidades políticas en tiempos de afrodescendencia: auto-identificación, ancestralidad, visibilidad y derechos. Eds. Alejandro Campos García y Silvia Valero. Buenos Aires: Corregidor, 2015. Impreso.

Obeso, Candelario. "Palabras al aire". La Ilustración (8 de septiembre de 1874): 276. Impreso.

Ruiz, Elio B. "La invisibilidad de Manzano". Afro Hispanic-Review 28 (2009): 167-183. Impreso.

Segato, Rita. La nación y sus otros: raza, etnicidad y diversidad religiosa en tiempos de políticas de la identidad. Buenos Aires: Prometeo, 2007. Impreso.

Valero, Silvia. "Afroepistemología y sensibilización en las narrativas históricas 'afrodescendientes' del siglo XXI". Identidades políticas en tiempos de afrodescendencia: auto-identificación, ancestralidad, visibilidad y derechos. Eds. Alejandro Campos García y Silvia Valero. Buenos Aires: Corregidor, 2015. 531-578. Impreso. 
"Antologías e historias literarias. El poder de definir identidades y (des)proveer de agencia literaria: el caso de los 'afrodescendientes' en Colombia". Estudios de Literatura Colombiana 21 (2007): 103-122. Impreso.

"¿De qué hablamos cuando hablamos de 'literatura afrocolombiana"? o los riesgos de las categorizaciones". Revista de Estudios de literatura colombiana 32 (2013): 7-15. 22 julio 2013. Web. 13 julio 2015.

"Invisibilidades directas y oblicuas. De cómo los discursos racistas 'oscurecieron' la producción 'afrodescendiente"'. Negritud: Fournal for Afro Caribbean-Afro Latin American Studies 1 (2007): 163-183. Impreso.

Zapata Olivella, Manuel. "La letra como instrumento de combate del negro". Letras Nacionales 35 (1977): 7. Impreso. 